\title{
The differences of sarcopenia-related phenotypes: effects of gender and population
}

\author{
Kai Zhong • Shu-feng Lei • Fang Yang • \\ Xiang-ding Chen $\cdot$ Li-jun Tan $\cdot$ Xue-zhen Zhu $•$ \\ Qing Tian • Hong-wen Deng
}

Received: 12 January 2011 / Accepted: 5 June 2011 /Published online: 7 July 2011

(C) European Group for Research into Elderly and Physical Activity (EGREPA) 2011

\begin{abstract}
Sarcopenia is a serious condition especially in the elderly population mainly characterized by the loss of skeletal muscle mass and strength with aging. Extremity skeletal muscle mass index (EMMI) (sum of skeletal muscle mass in arms and legs/height ${ }^{2}$ ) is gaining popularity in sarcopenia definition (less than two standard deviations below the mean of a young adult reference group), but little is known about the gender- and population-specific differences of EMMI. This study aimed at investigating the differences of EMMI, arm muscle mass index (AMMI), and leg muscle mass index (LMMI) between gender groups and populations (Chinese vs. Caucasians). The participants included 1,809 Chinese and 362 Caucasians with normal weight aged from 19 to 45 years old. Extremity muscle mass, arm muscle mass, and leg muscle mass were measured by using dual energy x-ray absorptiometry. Independent sample $t$ tests were used to analyze the differences in muscle mass indexes between the studied groups. All the study parameters
\end{abstract}

Kai Zhong and Shu-feng Lei contribute equally to this work.

K. Zhong $\cdot$ S.-f. Lei $\cdot$ F. Yang $\cdot$ X.-d. Chen $\cdot$ L.-j. Tan •

H.-w. Deng $(\bowtie)$

Laboratory of Molecular and Statistical Genetics and the Key

Laboratory of Protein Chemistry and Developmental Biology

of Ministry of Education, College of Life Sciences,

Hunan Normal University,

Changsha, Hunan 410081, People's Republic of China

e-mail: hwdeng@hunnu.edu.cn

Q. Tian · H.-w. Deng

Center of Bioinformatics and Genomics, School of Public Health and Tropical Medicine, Tulane University,

New Orleans, LA 70112, USA

X.-z. Zhu • H.-w. Deng

Center of Systematic Biomedical Research,

University of Shanghai for Science and Technology,

Shanghai 200093, People's Republic of China including EMMIs, AMMIs, and LMMIs were significantly higher $(P \leq 0.0003)$ in the Caucasian group than in the Chinese group and also higher in the male group than in the female group, and these significant differences $(P \leq 0.0005)$ remained after adjusting for age by simple regressions. The detected differences of muscle mass indexes between different gender and ethnic groups may provide important implications in their different risk of future sarcopenia.

Keywords Sarcopenia Extremity muscle mass · Gender . Population

\section{Introduction}

Sarcopenia is a serious condition mainly characterized by the loss of skeletal muscle mass (MM) and strength with aging [13], which is becoming recognized as a major cause of disability and morbidity in the elderly population [25, 44]. In addition, it imposes a heavy economic burden in the USA. In 2000, the estimated direct health care cost attributable to sarcopenia in the USA was $\$ 18.5$ billion, which represented about $1.5 \%$ of annual total health care expenditures [23].

Several parameters were used in measuring MM and were compared to investigate the effects of gender and population. Previous studies found that men had significantly higher $\mathrm{MM}$ in comparison with women in both absolute terms and relative to body mass $[1,6,15,16,18,22,50]$. Caucasians had significantly higher total body potassium, a measure of MM, than Asians [18]. American Caucasian women had significantly larger fat free weight and muscle thickness than Japanese women [21]. Europeans' MM was significantly larger than that of the Chinese [28]. However, these parameters (e.g., total body potassium) have more or less 
limitations in accurately evaluating sarcopenia due to the limited accuracy of measuring MM and no adjustment for body size.

Currently available techniques (such as dual energy $\mathrm{x}$ ray absorptiometry, DXA) make accurate measurement of extremity muscle mass (EMM sum of skeletal muscle mass in arms and legs) easy and cheap. Extremity skeletal muscle mass index (EMMI) (EMM/height $\left.{ }^{2}\right)$, a new parameter considering body size, is gaining popularity in sarcopenia definition (less than two standard deviations below the mean of a young adult reference group) [2,9], but little is known if there are gender- and population-specific differences of EMMI. This study aimed at investigating the differences in muscle mass indexes (MMIs) including EMMI, arm muscle mass index (AMMI), and leg muscle mass index (LMMI), in Chinese vs. Caucasians and in males vs. females.

\section{Materials and methods}

\section{Subjects}

The study was approved by the Creighton University Institutional Review Board and the Research Administration Department, Hunan Normal University. All the study subjects signed informed consent documents before entering the project. The study subjects came from a database that is created for studies to search for genes underlying the risk of osteoporosis and obesity. Only "healthy" people (defined by the following exclusion criteria) were included in the analysis. The exclusion criteria for the study subjects were histories of (1) serious residual effects of cerebral vascular disease; (2) diabetes mellitus, except for easily controlled, non-insulindependent diabetes mellitus (defined as adult asymptomatic hyperglycemia controlled by diet or oral agents); (3) chronic renal disease manifested by serum creatinine $>1.9 \mathrm{mg} / \mathrm{dl}$; (4) chronic liver disease or alcoholism; (5) significant chronic lung disease; (6) $>6$ months of corticosteroid therapy at pharmacologic levels; (7) $>6$ months of treatment with anticonvulsant therapy; (8) evidence of other metabolic or inherited bone disease, such as hyper- or hypoparathyroidism, Paget's disease, osteomalacia, or osteogenesis imperfecta; (9) rheumatoid arthritis or collagen disease; (10) recent (within the past year) major gastrointestinal disease, such as peptic ulcer, malabsorption, chronic ulcerative colitis, regional enteritis, or any significant chronic diarrhea state; (11) significant disease of any endocrine organ that would affect bone mass; (12) hyperthyroidism; (13) any neurologic or musculoskeletal condition that would be a nongenetic cause of low bone mass; and (14) any disease, treatment, or condition that would be a nongenetic cause of low bone mass. To minimize the confounding effect of overweight, we excluded the subjects with body mass index $(\mathrm{BMI}) \geq 25 \mathrm{~kg} / \mathrm{m}^{2}$.

\section{The Chinese sample}

A total of 1,809 unrelated subjects aged 19-45 years, who belong to the Chinese Han ethnic group, were recruited in Changsha City and its surrounding areas of central south of China.

\section{The Caucasian sample}

The sample contains a total of 362 unrelated Caucasian subjects aged from 19 to 45 years who were selected from more than 4,000 participants from 451 pedigrees recruited from Omaha, NE, USA. Individuals without consanguineous relationships are considered unrelated and selected for the present study. For example, if an individual was selected, his/ her children, cousins, siblings, parents, parents' siblings, and parents' siblings' children were not chosen, but the person who married the one in the pedigree was selected. The basic characteristics of the study subjects were listed in Table 1 .

\section{Measurements}

The MM of the Chinese was measured by a Hologic 4500 DXA scanner (Hologic Corp., Waltham, MA, USA) at Hunan
Table 1 Basic characteristics of the studied subjects

Values are means $\pm \mathrm{SD}$

$N$ no. of subjects

\begin{tabular}{|c|c|c|c|c|}
\hline & \multicolumn{2}{|l|}{ Women } & \multicolumn{2}{|l|}{ Men } \\
\hline & Chinese & Caucasians & Chinese & Caucasians \\
\hline$N$ & 851 & 232 & 958 & 130 \\
\hline Age (years) & $27.1 \pm 4.7$ & $34.0 \pm 7.1$ & $26.9 \pm 4.0$ & $32.4 \pm 8.0$ \\
\hline Weight (kg) & $50.4 \pm 5.7$ & $59.8 \pm 6.9$ & $60.5 \pm 6.7$ & $74.3 \pm 7.1$ \\
\hline Height $(\mathrm{cm})$ & $158.3 \pm 5.1$ & $165.5 \pm 6.2$ & $169.5 \pm 5.2$ & $180.9 \pm 6.5$ \\
\hline Body mass index $\left(\mathrm{kg} / \mathrm{m}^{2}\right)$ & $20.1 \pm 1.9$ & $21.8 \pm 2.0$ & $21.0 \pm 2.0$ & $22.7 \pm 1.7$ \\
\hline Percentage body fat (\%) & $27.7 \pm 4.9$ & $29.9 \pm 6.0$ & $15.0 \pm 5.3$ & $17.4 \pm 5.0$ \\
\hline
\end{tabular}


Normal University. The coefficient of variability $(\mathrm{CV})$ value for whole body muscle mass (WMM), the combination of EMM and trunk muscle mass, which was obtained from 30 subjects repeatedly measured two times, was $0.21 \%$ [53]. The MM of Caucasians was measured by Hologic $2000+$ or 4500 DXA scanners (Hologic, Bedford, MA, USA) in the Osteoporosis Research Center at Creighton University. The CV for WMM obtained on the Hologic 2000+ and 4500 DXA scanners was $1.0 \%$ and $0.7 \%$, respectively [10]. The calculation of MM has been previously described in detail elsewhere [51].

EMM was calculated as the combined sum of arm muscle mass and leg muscle mass. All scanners are calibrated daily, and long-term precision is monitored with external phantoms. Technicians maintain scan-by-scan surveillance for quality control in both America and China, and all of them were trained and certified by the International Society for Clinical Densitometry as Clinical Densitometrist. Therefore, MM measurements by different scanners and technicians in the study are highly compatible with one another and are well within the precision limits.

Body height and weight of all subjects were measured routinely in typical indoor clothing without shoes with a stadiometer and a standardized balance-beam scale at the time of DXA scan. MMIs were calculated as muscle mass/height ${ }^{2}$ (kilograms per meter squared).

\section{Statistical analysis}

Data were analyzed by using the Statistical Analysis System (SAS Institute, Cary, NC). The compared group data were normally distributed. Independent sample $t$ tests were used to analyze the effects of population (Chinese vs. Caucasians) and gender (women vs. men) on sarcopenia-related indexes. Since age is also correlated with MMI (Table 4), the effects of population and gender were also tested after adjustment by regressions for age. All statistical tests were two sided with statistical significance set at $P \leq 0.05$.

\section{Results}

\section{Basic characteristics}

The basic characteristics of the studied subjects were summarized in Table 1. The Caucasians were taller and weighed more, and had a higher BMI $(P<0.0001)$, compared with the Chinese within the same gender group, respectively, while males were higher and weighed more, and had a lower BMI $(P<0.0001)$, compared with the females within the same ethnic group, respectively. As shown in Table 4, age is significantly correlated with most of MMIs.
Differences between Chinese and Caucasian groups

The differences of MMIs between the Chinese and Caucasian groups are presented in Table 2. Within the same gender groups, the Caucasians were significantly $(P \leq 0.0003)$ higher than the Chinese for EMMI with a difference of $0.6 \mathrm{~kg} / \mathrm{m}^{2}$ (female) and $0.7 \mathrm{~kg} / \mathrm{m}^{2}$ (male), for LMMI with a difference of $0.3 \mathrm{~kg} / \mathrm{m}^{2}$ (female) and $0.2 \mathrm{~kg} / \mathrm{m}^{2}$ (male), and for AMMI with a difference of $0.3 \mathrm{~kg} / \mathrm{m}^{2}$ (female) and $0.5 \mathrm{~kg} / \mathrm{m}^{2}$ (male), respectively. After adjustment for age (Table 2), all these differences remain significant $(P \leq 0.0005)$.

\section{Differences between female and male groups}

The differences of MMIs between female and male groups are presented in Table 3. Within the same ethnic group, females were significantly $(P<0.0001)$ lower than males for EMMI with $1.9 \mathrm{~kg} / \mathrm{m}^{2}$ (Chinese) and $1.9 \mathrm{~kg} / \mathrm{m}^{2}$ (Caucasian), for LMMI with a difference of $1.2 \mathrm{~kg} / \mathrm{m}^{2}$ (Chinese) and $1.1 \mathrm{~kg} / \mathrm{m}^{2}$ (Caucasian), and for AMMI with a difference of $0.6 \mathrm{~kg} / \mathrm{m}^{2}$ (Chinese) and $0.8 \mathrm{~kg} / \mathrm{m}^{2}$ (Caucasian), respectively. After adjustment for age (Table 3), all these differences remain significant $(P<0.0001)$.

\section{Discussion}

The present results represented our first effort of investigating the differences in MMIs between Caucasian and Chinese groups, as well as female and male groups, and the results show there are consistently significant differences in MMIs between the pairs of study groups.

The Chinese group had lower MMIs than the Caucasian group, before and after adjustment for age (Table 4). Two possible mechanisms underline the observed population difference of MMIs between the Chinese and Caucasian groups: (1) lower testosterone concentration (TC) in the native Chinese than in Caucasians. Native Chinese men's levels of testosterone production and plasma testosterone were lower than those of Caucasian men from the USA [41]. Testosterone plays a key role in muscle hypertrophy $[19,26]$. (2) higher insulin resistance (IR) in the Chinese than in Caucasians. The Chinese had higher IR [12, 45], which characterized lower insulin sensitivity (IS), than Caucasians. IR can accelerate muscle protein degradation in numerous studies [29, 35, 43, 52].

Females had lower MMI than males, before and after adjustment for age. Likewise, the lower MMI in females is probably due to their lower serum TC [7] and IS [14, 17, 34]. In fact, numerous previous studies have constantly reported that TC is significantly positively associated with IS in vivo $[24,38,40,46,54]$, and both of them can be improved with 


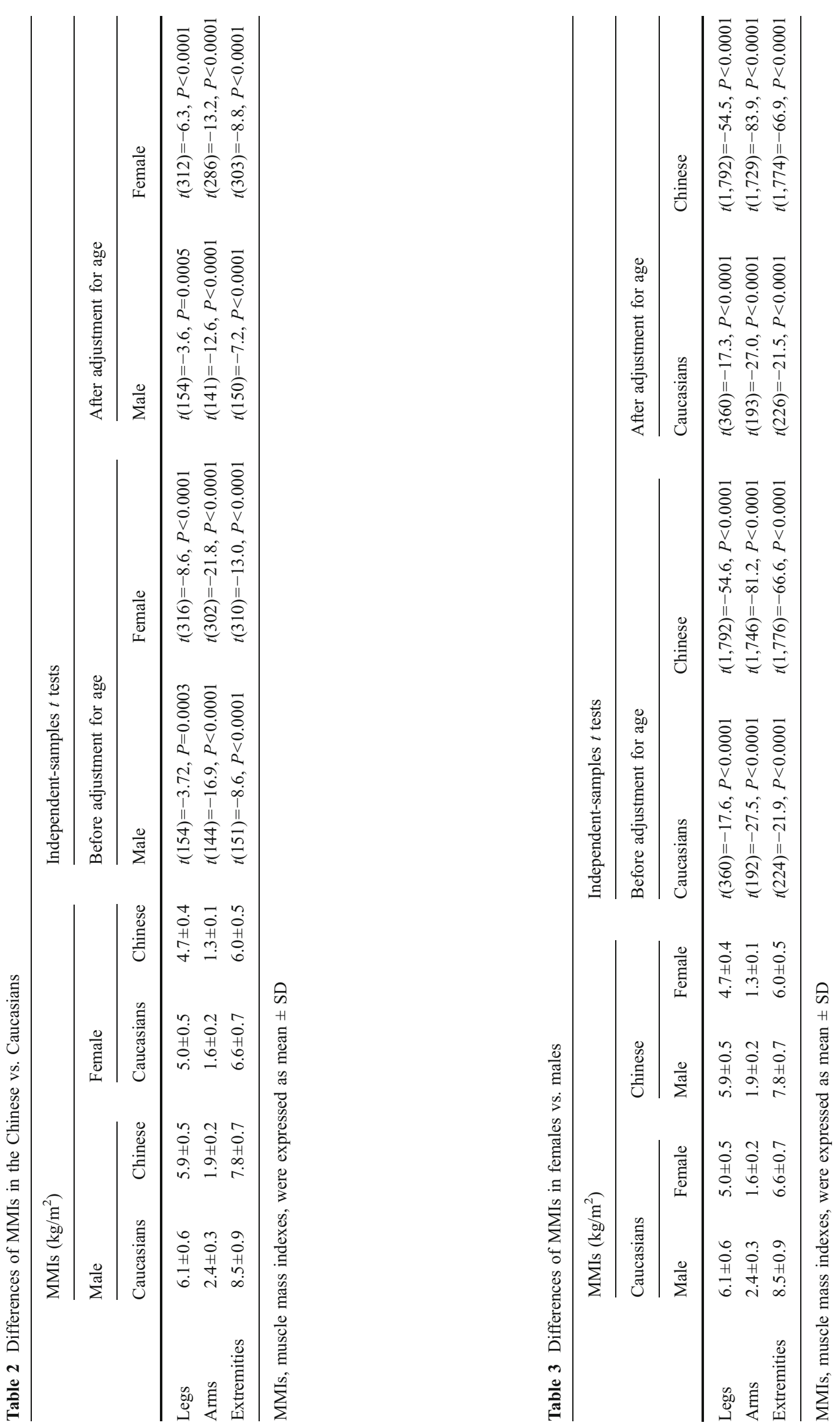


exercise $[3,5,11,20,36,37,42,48]$. The increased plasma $\mathrm{TC}$ in male rats during exercise is at least partially a result of lactate's effect on the secretion of testosterone [30, 31], and testosterone may suppress the expression of proinflammatory cytokines such as tumor necrosis factor-alpha and interleukin1 [8, 32]. In experimental models, these proinflammatory cytokines disrupt normal insulin action in fat and muscle cells, and this may be the major factor in causing the whole body IR observed in patients with visceral adiposity [47]. In addition, cholesterol, a precursor of testosterone, comes for about one third from the dietary intake and for about two thirds from endogenous synthesis from unburned food metabolites [27]; thus, different cholesterol intake from food may also impose a significant impact on plasma TC and consequently the IS in skeletal muscle. However, due to the lack of data of physical activity/exercise and nutrition/food in the current study, it is impossible to investigate their effects on the differences in MMIs.

Several approaches, e.g., DXA, total body potassium, isotope dilution for total body water, total body electrical conductivity, bioelectrical impedance analysis, and bioelectrical impedance spectroscopy, vary in their accuracy, complexity, cost, and availability, are available for MM measurement. DXA is gaining popularity in MM measurement because it is relatively quick and accurate to measure MM especially for EMM [39] with low radiation dose [33].

Currently, EMM is gaining popularity in sarcopenia definition [2,9]. WMM is a previous important measure for sarcopenia [49]; however, current available methods are difficult to accurately measure the WMM in vivo because internal organs such as the brain, heart, and liver have relatively similar physical characteristics (e.g., density) compared with muscles and thus have confounding effects to evaluate MM. However, the extremities largely consist of fat mass, bone mass, and muscles, and DXA can accurately measure these three components [4]. So in this study, we focused on investigating the difference of EMMI, as well as AMMI and LMMI, which only takes skeletal MM into consideration, between different gender and ethnic groups.

The development of sarcopenia is determined by the peak MM attained early in young adults and subsequent rate of muscle loss with aging later in life. At the current relatively early stage, due to easy recruitment of subjects with peak MM and relative difficulty in recruiting samples for tracking MM loss, most of the studies for sarcopenia focused on peak MM. This study also focused on peak $\mathrm{MM}$, as evidenced by the sample age span (19-45 years) when the peak $\mathrm{MM}$ is maintained. Investigating the difference in peak MMI between different ethnic and gender groups may shed some light on explaining the differences of sarcopenia risk. It would be highly beneficial for future studies to increase efforts to study MM loss for eventually elucidating the pathology of sarcopenia. 
In conclusion, the present results demonstrate that before and even after adjustment for age, the Caucasian and male groups had significantly higher MMIs in comparison with the Chinese and female groups, respectively, and these findings may provide important implications in the genderand population-specific risks of future sarcopenia among different gender and ethnic groups.

Acknowledgments The study was partially supported by the Natural Science Foundation of China (NSFC) (30600364, 31071097, 30771222, and 30900810), NSFC-CIHR (Canadian Institutes of Health Research) Joint Health Research Initiative Proposal (30811120436), NSFC/RGC (Research Grants Council) Joint Research Scheme (30731160618), and Shanghai Leading Academic Discipline Project (S30501) and startup fund from the Shanghai University of Science and Technology. HWD was partially supported by grants from NIH (R03TW008221, R01AR050496, R01AG026564, R01AR057049, and P50AR055081) and Edward G. Schlieder Endowed Chair.

\section{References}

1. Abe T, Kearns CF, Fukunaga T (2003) Sex differences in whole body skeletal muscle mass measured by magnetic resonance imaging and its distribution in young Japanese adults. Br J Sports Med 37(5):436-440

2. Baumgartner RN, Koehler KM, Gallagher D, Romero L, Heymsfield SB, Ross RR et al (1998) Epidemiology of sarcopenia among the elderly in New Mexico. Am J Epidemiol 147(8):755-763

3. Borghouts LB, Keizer HA (2000) Exercise and insulin sensitivity: a review. Int J Sports Med 21(1):1-12

4. Burkhart TA, Arthurs KL, Andrews DM (2009) Manual segmentation of DXA scan images results in reliable upper and lower extremity soft and rigid tissue mass estimates. J Biomech 42 (8):1138-1142

5. Chad CL, Wang JK (1998) A brief review: testosterone and resistance exercise in men. J Strength Cond Res 12(1):57-63

6. Chong CK, Tseng CH, Tai TY, Wong MK (1995) Body composition and its relationship with physical activity and anthropometric factors in Chinese adults. J Formos Med Assoc 94(8):481-486

7. Christiansen K (2001) Behavioural effects of androgen in men and women. J Endocrinol 170(1):39-48

8. Corcoran MP, Meydani M, Lichtenstein AH, Schaefer EJ, Dillard A, Lamon-Fava S (2010) Sex hormone modulation of proinflammatory cytokine and C-reactive protein expression in macrophages from older men and postmenopausal women. J Endocrinol 206(2):217-224

9. Delmonico MJ, Harris TB, Lee JS, Visser M, Nevitt M, Kritchevsky SB et al (2007) Alternative definitions of sarcopenia, lower extremity performance, and functional impairment with aging in older men and women. J Am Geriatr Soc 55(5):769-774

10. Deng HW, Deng H, Liu YJ, Liu YZ, Xu FH, Shen H et al (2002) A genomewide linkage scan for quantitative-trait loci for obesity phenotypes. Am J Hum Genet 70(5):1138-1151

11. Devlin JT (1992) Effects of exercise on insulin sensitivity in humans. Diabetes Care 15(11):1690-1693

12. Dickinson S, Colagiuri S, Faramus E, Petocz P, Brand-Miller JC (2002) Postprandial hyperglycemia and insulin sensitivity differ among lean young adults of different ethnicities. J Nutr 132 (9):2574-2579

13. Evans WJ (1995) What is sarcopenia? J Gerontol A Biol Sci Med Sci 50 Spec No:5-8
14. Flanagan DE, Vaile JC, Petley GW, Phillips DI, Godsland IF, Owens P et al (2007) Gender differences in the relationship between leptin, insulin resistance and the autonomic nervous system. Regul Pept 140(1-2):37-42

15. Gallagher D, Heymsfield SB (1998) Muscle distribution: variations with body weight, gender, and age. Appl Radiat Isot 49(5-6):733734

16. Gallagher D, Visser M, De Meersman RE, Sepulveda D, Baumgartner RN, Pierson RN et al (1997) Appendicular skeletal muscle mass: effects of age, gender, and ethnicity. J Appl Physiol 83(1):229-239

17. Geer EB, Shen W (2009) Gender differences in insulin resistance, body composition, and energy balance. Gend Med 6(Suppl 1):60 75

18. He Q, Heo M, Heshka S, Wang J, Pierson RN Jr, Albu J et al (2003) Total body potassium differs by sex and race across the adult age span. Am J Clin Nutr 78(1):72-77

19. Herbst KL, Bhasin S (2004) Testosterone action on skeletal muscle. Curr Opin Clin Nutr Metab Care 7(3):271-277

20. Holloszy JO (2005) Exercise-induced increase in muscle insulin sensitivity. J Appl Physiol 99(1):338-343

21. Ishida Y, Kanehisa H, Fukunaga T, Pollock ML (1992) A comparison of fat and muscle thickness in Japanese and American women. Ann Physiol Anthropol 11(1):29-35

22. Janssen I, Heymsfield SB, Wang ZM, Ross R (2000) Skeletal muscle mass and distribution in 468 men and women aged 18 88 yr. J Appl Physiol 89(1):81-88

23. Janssen I, Shepard DS, Katzmarzyk PT, Roubenoff R (2004) The healthcare costs of sarcopenia in the United States. J Am Geriatr Soc 52(1):80-85

24. Kapoor D, Goodwin E, Channer KS, Jones TH (2006) Testosterone replacement therapy improves insulin resistance, glycaemic control, visceral adiposity and hypercholesterolaemia in hypogonadal men with type 2 diabetes. Eur J Endocrinol 154(6):899-906

25. Karakelides H, Nair KS (2005) Sarcopenia of aging and its metabolic impact. Curr Top Dev Biol 68:123-148

26. Katznelson L, Finkelstein JS, Schoenfeld DA, Rosenthal DI, Anderson EJ, Klibanski A (1996) Increase in bone density and lean body mass during testosterone administration in men with acquired hypogonadism. J Clin Endocrinol Metab 81(12):43584365

27. Kervizic G, Corcos L (2008) Dynamical modeling of the cholesterol regulatory pathway with Boolean networks. BMC Syst Biol 2:99

28. Lear SA, Kohli S, Bondy GP, Tchernof A, Sniderman AD (2009) Ethnic variation in fat and lean body mass and the association with insulin resistance. J Clin Endocrinol Metab 94(12):4696-4702

29. Lee SW, Park GH, Song JH, Hong KC, Kim MJ (2007) Insulin resistance and muscle wasting in non-diabetic end-stage renal disease patients. Nephrol Dial Transplant 22(9):2554-2562

30. Lin H, Wang SW, Wang RY, Wang PS (2001) Stimulatory effect of lactate on testosterone production by rat Leydig cells. J Cell Biochem 83(1):147-154

31. Lu SS, Lau CP, Tung YF, Huang SW, Chen YH, Shih HC et al (1997) Lactate and the effects of exercise on testosterone secretion: evidence for the involvement of a cAMP-mediated mechanism. Med Sci Sports Exerc 29(8):1048-1054

32. Malkin CJ, Pugh PJ, Jones RD, Kapoor D, Channer KS, Jones TH (2004) The effect of testosterone replacement on endogenous inflammatory cytokines and lipid profiles in hypogonadal men. $\mathrm{J}$ Clin Endocrinol Metab 89(7):3313-3318

33. Mazess RB, Barden HS, Bisek JP, Hanson J (1990) Dual-energy $\mathrm{X}$-ray absorptiometry for total-body and regional bone-mineral and soft-tissue composition. Am J Clin Nutr 51(6):1106-1112

34. Mittendorfer B (2005) Insulin resistance: sex matters. Curr Opin Clin Nutr Metab Care 8(4):367-372 
35. Moxley RT 3rd, Griggs RC, Goldblatt D, VanGelder V, Herr BE, Thiel R (1978) Decreased insulin sensitivity of forearm muscle in myotonic dystrophy. J Clin Invest 62(4):857-867

36. Nakai N, Shimomura Y, Ohsaki N, Sato J, Oshida Y, Ohsawa I et al (1996) Exercise training prevents maturation-induced decrease in insulin sensitivity. J Appl Physiol 80(6):1963-1967

37. Nindl BC, Kraemer WJ, Gotshalk LA, Marx JO, Volek JS, Bush FA et al (2001) Testosterone responses after resistance exercise in women: influence of regional fat distribution. Int J Sport Nutr Exerc Metab 11(4):451-465

38. Osuna JA, Gomez-Perez R, Arata-Bellabarba G, Villaroel V (2006) Relationship between BMI, total testosterone, sex hormone-binding-globulin, leptin, insulin and insulin resistance in obese men. Arch Androl 52(5):355-361

39. Pintauro SJ, Nagy TR, Duthie CM, Goran MI (1996) Crosscalibration of fat and lean measurements by dual-energy X-ray absorptiometry to pig carcass analysis in the pediatric body weight range. Am J Clin Nutr 63(3):293-298

40. Rabijewski M, Kozakowski J, Zgliczynski W (2005) The relationship between testosterone and dehydroepiandrosterone sulfate concentrations, insulin resistance and visceral obesity in elderly men. Endokrynol Pol 56(6):897-903

41. Santner SJ, Albertson B, Zhang GY, Zhang GH, Santulli M, Wang $\mathrm{C}$ et al (1998) Comparative rates of androgen production and metabolism in Caucasian and Chinese subjects. J Clin Endocrinol Metab 83(6):2104-2109

42. Shih KC, Janckila AJ, Kwok CF, Ho LT, Chou YC, Chao TY (2010) Effects of exercise on insulin sensitivity, inflammatory cytokines, and serum tartrate-resistant acid phosphatase 5a in obese Chinese male adolescents. Metabolism 59(1):144-151

43. Siew ED, Pupim LB, Majchrzak KM, Shintani A, Flakoll PJ, Ikizler TA (2007) Insulin resistance is associated with skeletal muscle protein breakdown in non-diabetic chronic hemodialysis patients. Kidney Int 71(2):146-152

44. Sipila S, Heikkinen E, Cheng S, Suominen H, Saari P, Kovanen V et al (2006) Endogenous hormones, muscle strength, and risk of fall-related fractures in older women. J Gerontol A Biol Sci Med Sci 61(1):92-96
45. Torrens JI, Skurnick J, Davidow AL, Korenman SG, Santoro N, Soto-Greene $M$ et al (2004) Ethnic differences in insulin sensitivity and beta-cell function in premenopausal or early perimenopausal women without diabetes: the Study of Women's Health Across the Nation (SWAN). Diabetes Care 27(2):354-361

46. Traish AM, Saad F, Guay A (2009) The dark side of testosterone deficiency: II. Type 2 diabetes and insulin resistance. J Androl 30 (1):23-32

47. Tselepis C, Perry I, Dawson C, Hardy R, Darnton SJ, McConkey $\mathrm{C}$ et al (2002) Tumour necrosis factor-alpha in Barrett's oesophagus: a potential novel mechanism of action. Oncogene 21 (39):6071-6081

48. Vingren JL, Kraemer WJ, Ratamess NA, Anderson JM, Volek JS, Maresh CM (2010) Testosterone physiology in resistance exercise and training: the up-stream regulatory elements. Sports Med 40 (12):1037-1053

49. Visser M (2009) Towards a definition of sarcopenia-results from epidemiologic studies. J Nutr Health Aging 13(8):713-716

50. Wang J, Horlick M, Thornton JC, Levine LS, Heymsfield SB, Pierson RN Jr (1999) Correlations between skeletal muscle mass and bone mass in children 6-18 years: influences of sex, ethnicity, and pubertal status. Growth Dev Aging 63(3):99-109

51. Wang W, Wang Z, Faith MS, Kotler D, Shih R, Heymsfield SB (1999) Regional skeletal muscle measurement: evaluation of new dual-energy X-ray absorptiometry model. J Appl Physiol 87 (3): $1163-1171$

52. Wang X, Hu Z, Hu J, Du J, Mitch WE (2006) Insulin resistance accelerates muscle protein degradation: activation of the ubiquitinproteasome pathway by defects in muscle cell signaling. Endocrinology 147(9):4160-4168

53. Wu S, Lei SF, Chen XD, Tan LJ, Jian WX, Deng FY et al (2007) The contributions of lean tissue mass and fat mass to bone geometric adaptation at the femoral neck in Chinese overweight adults. Ann Hum Biol 34(3):344-353

54. Yeap BB, Chubb SA, Hyde Z, Jamrozik K, Hankey GJ, Flicker L et al (2009) Lower serum testosterone is independently associated with insulin resistance in non-diabetic older men: the Health In Men Study. Eur J Endocrinol 161(4):591-598 